Portland State University

PDXScholar

$12-17-2017$

\title{
Spatial Transferability Assessment of a Composite Walkability Index: The Pedestrian Index of the Environment (PIE)
}

\author{
Gabriel Lefebvre-Ropars \\ Polytechnique Montréal \\ Catherine Morency \\ Polytechnique Montréal \\ Patrick A. Singleton \\ Utah State University \\ Kelly J. Clifton \\ Portland State University, kclifton@pdx.edu
}

Follow this and additional works at: https://pdxscholar.library.pdx.edu/cengin_fac

Part of the Civil and Environmental Engineering Commons, and the Urban Studies and Planning Commons

Let us know how access to this document benefits you.

\section{Citation Details}

Lefebvre-Ropars, Gabriel; Morency, Catherine; Singleton, Patrick A.; and Clifton, Kelly J., "Spatial Transferability Assessment of a Composite Walkability Index: The Pedestrian Index of the Environment (PIE)" (2017). Civil and Environmental Engineering Faculty Publications and Presentations. 420. https://pdxscholar.library.pdx.edu/cengin_fac/420

This Post-Print is brought to you for free and open access. It has been accepted for inclusion in Civil and Environmental Engineering Faculty Publications and Presentations by an authorized administrator of PDXScholar. Please contact us if we can make this document more accessible: pdxscholar@pdx.edu. 


\section{SPATIAL TRANSFERABILITY ASSESSMENT OF A COMPOSITE WALKABILITY INDEX: THE PEDESTRIAN INDEX OF THE ENVIRONMENT (PIE)}

43

44

Gabriel Lefebvre-Ropars, Master's Student (corresponding author)

Department of Civil, Geological and Mining Engineering

Polytechnique Montréal, C.P. 6079, Station Centre-Ville

Montreal (Quebec) CANADA H3C 3A7

Tel: (514) 340-4711 \#4157

Email: gabriel-lee.lefebvre-ropars@polymtl.ca

Catherine Morency, Ph.D., P.Eng., Full Professor

Head of the Mobilité Research Chair

Department of Civil, Geological and Mining Engineering

Polytechnique Montréal, C.P. 6079, Station Centre-Ville

Montreal (Quebec) CANADA H3C 3A7

Tel: (514) 340-4711 \#4502

Email: cmorency@polymtl.ca

Patrick A. Singleton, Ph.D., Assistant Professor

Department of Civil and Environmental Engineering

Utah State University

4110 Old Main Hill

Logan (Utah) UNITED STATES 84322-4110

Phone: 435-797-7109

Email: patrick.singleton@usu.edu

Kelly J. Clifton, Ph.D., Professor

Department of Civil and Environmental Engineering

Portland State University

PO Box 751-CEE

Portland (Oregon) UNITED STATES 97207-0751

Phone: 503-725-2871

Fax: 503-725-5950

Email: kclifton@pdx.edu

August $26^{\text {th }}, 2017$ 


\section{ABSTRACT}

This paper analyzes the transferability of a composite walkability index, the Pedestrian Index of the Environment (PIE), to the Greater Montréal Area (GMA). The PIE was developed in Portland, Oregon, and is based on proprietary data. It combines six urban form variables into a score ranging from 20 to 100 . The measure introduces several methodological refinements which have not been applied concurrently in previous efforts: a wide coverage of the different dimensions of the urban form, together with the use of a distance-based decay function and modelling-based weighing of the variables.

This measure is applied to the GMA using local data in order to evaluate the feasibility of its transfer (the possibility of locally replicating the measure). It is then included in a series of mode choice models to assess its transferability (the capacity of the measure to describe walkability and predict mode choice in another urban area). The models, segmented by trip distance or trip purpose, are estimated and validated against observed trip data from the 2013 Origin-Destination survey.

Significant positive correlation is found between the PIE and the choice of walking for short trips, for all purposes as well as for four specific trip purposes. The inclusion of the PIE also improves the accuracy of the modelling process as well as the prediction of the choice of walking for short trips. The PIE can therefore be used in the GMA, and potentially in other metropolitan areas, to improve the modelling of travel behavior for short trips.

Keywords: walkability index, walking behavior, active transportation, modal choice, neighborhood variables, built environment 


\section{INTRODUCTION}

From the turn of the $21^{\text {st }}$ century, obesity has been recognized as a global epidemic by the World Health Organization (Organisation mondiale de la Santé, 2000). Many contributing factors to this trend have been identified, one of which is the increasing dependency of daily travel on motorized modes and the corresponding reduction in physical activity. However, there is growing evidence that neighborhoods planned and designed around the notion of walkability can encourage physical activity among both young people and adults, as well as generate economic benefits and improve the social equity of cities (Handy, 2005; Leinberger and Lynch, 2016).

An important effort has been undertaken in the last few decades by the research community to identify the critical variables relative to the urban form that have the largest impact on walking behavior in urban and suburban neighborhoods. These variables can be grouped into 5 categories, referred to as the 5 D's: Density, Diversity, Design, Destination accessibility and Distance to transit (Ewing and Cervero, 2010). While there is growing evidence of the explanatory power of those neighborhood variables, they tend to be strongly correlated to one another when used in a modelling context. This can force the researcher to omit one or several of the variables when building a model (Wong et al., 2011). To circumvent this problem, a common solution has been to combine several variables into a single index representing the urban form when studying determinants of walking.

From the rapidly growing body of literature, fueled by different perspectives such as urban studies, geography, public health and transportation planning, a great number of walkability indices have emerged (Maghelal and Capp, 2011; Vale et al., 2015). Existing measures include different variables, depending on the theoretical underpinning of the method used and the local availability of data. While a lot of measures exist as of today (more than 80 , according to Vale et al. (2015)), few of the indices proposed in the literature have been validated against actual survey data and even less have been transferred to another spatial context for validation (Maghelal and Capp, 2011). Particular attention should also be paid to trip-related variables associated with walking behavior, since the correlation between walkability of the urban environment and the decision to walk has been shown to be partially mediated by the trip's length (Morency et al., 2011) and purpose (Manaugh and El-Geneidy, 2011).

Moreover, there does not seem to be a consensus on which variables relative to the urban form should be included within such a measure. Table 1 shows the variety of variables included in eight selected walkability indices, all of which have been correlated with active transportation behaviors. Those indices are:

- The Walkability Index (WI), most popular in the literature (Saelens et al., 2003)

- The Walk Score ${ }^{\circledR}$, a commercial solution (WS) (Koschinsky et al., 2016)

- The Walk Opportunity Index (WOI) (Kuzmyak et al., 2006)

- The Walkability Scale (WS) (Freeman et al., 2012)

- The Pedshed (Ps) (Porta and Renne, 2005)

- The Extended Walkability Index (EWI) and Moveability Index (MI) (Buck et al., 2014)

- The Neighborhood Destination Accessibility Index (NDAI) (Witten et al., 2011)

- The Pedestrian Index of the Environment (PIE), the focus of this paper (Singleton et al., 2014) 
Table 1: Composition of eight different walkability indices

\begin{tabular}{|c|c|c|c|c|c|c|c|c|c|}
\hline Variables & WI & WS & WOI & Ps & EWI & MI & NDAI & PIE & $\begin{array}{l}\text { Variable } \\
\text { count }\end{array}$ \\
\hline Residential density & $\bar{X}$ & & & & $\bar{X}$ & $\mathrm{X}$ & & & 3 \\
\hline Population density & & & & & & & & $\mathrm{X}$ & 1 \\
\hline Land use diversity & $\mathrm{X}$ & & & & $\mathrm{X}$ & $\mathrm{X}$ & & & 3 \\
\hline Intersection density/Block size & $\mathrm{X}$ & $\mathrm{X}$ & & & $\mathrm{X}$ & $\mathrm{X}$ & & $\mathrm{X}$ & 5 \\
\hline Intersection types & & $\mathrm{X}$ & $\mathrm{X}$ & & & & & & 2 \\
\hline Infrastructure comfort & & & & & & & & $\mathrm{X}^{*}$ & 1 \\
\hline Network directness & & & & $\mathrm{X}$ & & & & & 1 \\
\hline Services and opportunities & $\mathrm{X}$ & $\mathrm{X}$ & $\mathrm{X}$ & & & & $\mathrm{X}$ & $\mathrm{X}$ & 5 \\
\hline Green space supply & & & & & & $\mathrm{X}$ & $\mathrm{X}$ & & 1 \\
\hline Transit supply & & & & & $\mathrm{X}$ & $\mathrm{X}$ & $\mathrm{X}$ & $\mathrm{X}$ & 3 \\
\hline Number of included variables & 4 & 3 & 2 & 1 & 4 & 5 & 3 & $\overline{6}$ & \\
\hline
\end{tabular}

* The PIE includes two distinct variables related to this category: infrastructure comfort and sidewalk density

The focus of this paper is to explore the potential of one of those composite indices, the Pedestrian Index of the Environment (PIE) (Singleton et al., 2014), to explain short walking trips in the Greater Montreal Area (GMA). The PIE shows great potential to represent the pedestrian environment in modelling applications. It has already proven useful in improving the accuracy of a pedestrian travel demand model under development in the Portland region (Clifton et al., 2016a). The measure introduces several methodological refinements which have not been applied concurrently in previous efforts:

- It covers the 5 D's of the urban form as described by Ewing and Cervero (2010);

- It weighs opportunities according to their distance from the reference point;

- It assigns a relative weight to each variable according to its direct relationship with walking behavior;

However, the PIE, in its original formulation, depends on a database (the Context Tool) maintained by Metro Portland, the regional transportation planning agency. The goals of this paper are twofold: 1) to examine the feasibility of transferring the index to another metropolitan region, in this case the GMA, and 2) to explore its potential to explain the correlation between the urban form and the decision to walk for short trips in the new region. This means assessing the index's transfer (the possibility of replicating the measure with local datasets) as well as its transferability (the capacity of the measure to describe walkability in another urban area), as described by Yasmin et al. (2015).

Assessing the spatial transfer and transferability of walkability measures is a critical step for research and practice. Examining measures of walkability in different metropolitan regions is 
an important step towards validating a given construct for use in practical transportation planning and modeling applications. Different regions may have different availabilities and qualities of data, which may prohibit or facilitate the use of a particular walkability index. Furthermore, it is useful to investigate whether the association between a walkability index and walking behavior is similar in a different region using different data, or whether this relationship diverges based on local idiosyncrasies.

This paper aims to assess the transferability of the PIE with local data, while considering trip purpose and length, as well as its contribution to the modelling of mode choice for short trips.

\section{METHODS}

\subsection{Datasets}

\subsubsection{The Origin-Destination Survey}

Conducted every five years, the Montréal Origin-Destination (OD) survey is a phone interview-based travel survey that samples roughly $5 \%$ of the households in the metropolitan area, which amounts to more than 78,000 households. Participants are recruited through a random sample based on landline and cell phone listings. Sample validation is carried out against census data from the 2011 Canadian Census of Population. Such surveys have been conducted since the early 1970s in theGMA. The survey method has evolved over time and relies on a rigorous methodology to assure representativeness of population segments over space. The survey process is supervised by a technical committee uniting the main transportation authorities in the region. In the recent surveys, a computer-assisted telephone interviewing (CATI) tool is used during the interview and performs real-time validation of the declared information. Two other tools assist the survey conduct: one for the sampling management, namely the renewal of the sample and the fulfillment of sampling strata, and one for the monitoring of the interviews with daily statistics on duration, interviewers' performance, etc. The software tools are described in (Chapleau et al., 2001). Data validation is performed during the interview using reference datasets on the transportation networks, addresses, intersections and trip generators, as well after the interviews for consistency of individual trips and within household members. The sample is then weighted to represent the reference population, as measured by the 2011 Census of Population. Specific details of the procedure are not publicly available. However, more details can be found in the official OD survey summary (Secrétariat à l'enquête Origine-Destination, 2013).

Analysis and models presented in this article are based on the 2013 survey dataset (version 13.2b), collected in the fall of 2013. The OD survey collects georeferenced information on each trip carried out by all members of a household over four years old on the last business day before the interview. Detailed information is collected about each trip: the location of its origin and destination, its purpose, the time of departure as well as the mode sequence. The survey also collects data relative to the households - namely their size and car ownership, as well as the home location - and the individuals - their age, gender and work status as well as whether they possess a driving license.

It is worth noting that in the OD dataset, walking is explicitly recorded only when it is the only mode used between the origin and the destination of a trip. Pedestrian activity occurring as part of a trip using another mode is not recorded as a walking trip. A trip where the individual walks from their home to the bus stop, then takes the bus towards their destination stop and walks from that stop to their workplace will be considered as a transit trip and will include no information about the segments traveled on foot. This matches the definition of walk trips in the Portland dataset originally used to develop the PIE. 
A trip chaining binary variable was computed from the trip database using a methodology developed by Valiquette (2010). Trip chains are defined as the sequence of trips occurring between the moment when individuals leave their home and the moment where they return (Primerano et al., 2008). The trip chaining variable classifies trips into two categories: simple trip chains (home $\rightarrow$ activity $1 \rightarrow$ home) and complex trip chains (home $\rightarrow$ activity $1 \rightarrow \ldots \rightarrow$ activity $n \rightarrow$ home). This makes it possible to take into account the constraints that can be imposed on modal choice for a given trip by the requirements of previous or subsequent trips.

A shortest path distance between all origins and destinations was also computed using the OSRM calculator (Luxen and Vetter, 2011). Trip data for which the production was located in the GMA were extracted from the database, for a total of 356,503 recorded trips. Records with incomplete socio-demographic information or invalid trip chaining data or network distance were discarded, as well as return home trips, leaving 184,538 trips in the study database, which represents $51,76 \%$ of the original database.

\subsubsection{Urban form variables}

The variables used to calculate the PIE were extracted from a variety of sources:

- OpenStreetMap's (OSM) road network centerlines (April 2016);

- The CMM (Montreal Metropolitan Community)'s land use polygons (2014);

- Statistics Canada's Census of Population data at the census tract (CT) level (2011);

- Archived GTFS points from GTFS Data Exchange (2013);

- Environics Analytics EAG Business Locations database (2012).

The 2011 Census of Population database is supplied by Canada's federal statistics agency, Statistics Canada. Information on data quality and coverage can be found on the 2011 Census Program portal (Statistique Canada, 2011, 2015). The land use dataset is produced by the CMM using municipal property assessment rolls aggregated by the provincial government. Adjacent properties sharing the same principal use are aggregated to form land use zones. The property limits used in this process are extracted from the official provincial land register or, when the information is not available, from a combination of digitized maps and orthophotographs. Complementary methodological information is available on the CMM's open data portal, the Observatoire Grand Montréal (Communauté métropolitaine de Montréal). The GTFS feeds were structured by the transit agencies themselves in the case of the 3 largest operators (the STM, the STL and the RTL) or by the metropolitan transit agency (the AMT in 2013) in the case of the smaller operators. These feeds represent transit service as planned by the transportation authorities. The datasets are structured and validated according to the GTFS specification (Google, 2016). The EAG Business Location database is maintained by a private company that aggregates commercial information based on data collected by Statistics Canada. An annual validation of the listed businesses' names, location and industry is carried out by telephone and a cleaning process identifies and flags duplicate records (Environics Analytics, 2012). OSM is a crowdsourced project where datasets are built and maintained by a community of volunteers. More and more researchers are using OSM data as its reliability has been established in a North American context, especially for pedestrian networks (Zielstra and Hochmair, 2012), and its accuracy been found to be comparable to official government cartographic data (Haklay, 2010; Haklay et al., 2010).

For each database, records located in the GMA are extracted using PostGIS 2.2.0. The 
GMA is defined in this paper as the shared area between the CMM's administrative boundary and the Montréal Census Metropolitan Area (CMA) in order to ensure completeness of the datasets.

\subsection{Building the Pedestrian Index of the Environment}

The PIE was elaborated as part of a process to develop a new modelling tool for walking trips in Metro Portland's four-step model (Clifton et al., 2016a, b). The measure uses, as an input, the 1-to-5 scores assigned to six neighborhood variables estimated by Metro Portland's Context Tool, a GIS-based planning tool (Oregon Metro). The variables are:

- Comfortable facilities

- Block size

- People per $\mathrm{km}^{2}$ (population + employment)

- Sidewalk density

- Transit access

- Urban Living Infrastructure (amenities)

The PIE thus includes measures of density, diversity and design, as well as transit supply and accessibility to destinations, covering the 5 D's of urban form (Ewing and Cervero, 2010). Each variable is computed through the use of a kernel density algorithm which represents the decreasing impact of urban features on walking behavior as distance increases (Duncan et al., 2012). Each variable is then weighed relative to the other variables according to its modelled relationship with walk trips. Their sum is normalized on a 20 to 100 scale (Singleton et al., 2014). The index was successful in explaining and predicting active transportation behavior-walk mode choice and pedestrian destination choice - in the Portland region (Clifton et al., 2016a, b).

A major roadblock to the transfer of the PIE to another metropolitan area lies in the fact that the Portland implementation of the PIE is based on the Context Tool's pre-calculated scores. After discussions with Oregon Metro's Senior GIS Specialist responsible for the Context Tool, a replication methodology was developed:

1. Structure the input datasets

2. Build the spatial analysis units

3. Compute variables using a kernel density algorithm

4. Classify values using natural breaks classification

5. Estimate mode choice models for each variable to obtain weights

6. Sum and normalize weighted variables to obtain PIE score

\subsubsection{Structure of the input datasets}

In order to be computed by a kernel density algorithm in a GIS environment, every input dataset has to be transformed into a point layer with spatial coordinates and a weight for every record. The weighing procedure was adapted from Oregon Metro's procedures.

\subsection{Comfortable facilities}

Each segment of the OSM centerline file over $1 \mathrm{~m}$ (3.28 ft.) long is classified as low, medium or high comfort according to the functional classification of the road, with highways and 
other infrastructure inaccessible to pedestrians being excluded from the dataset. Segment length is then weighted per their comfort level: low comfort segments are assigned a weight of -1 , medium comfort segments a weight of 1 and high comfort segments a weight of 2 .

\subsection{Block size}

The Block size variable is computed by merging contiguous lots from the CMM land use dataset, excluding streets, alleys, railways and water bodies. Blocks are then ranked by quartiles of their area and the quartile is used as the kernel density weight. The largest blocks are assigned a weight of 1 and the smallest blocks a weight of 4 . Blocks with an area of less than $250 \mathrm{~m}^{2}(9.65$ sq. mi) are excluded, as they generally consist of traffic medians.

\subsection{People per $\mathbf{k m}^{2}$}

The People per $\mathrm{km}^{2}$ could not be computed using a kernel density since the information available from the Canadian census is not available as disaggregated points, but is rather aggregated at the census tract (CT) level. A conventional density ([(inhabitants + jobs)/CT area $]$ ) is thus computed for that variable.

\subsection{Sidewalk density}

Due to the unavailability of reliable and consistent data on the location of sidewalks in the GMA, the Sidewalk density variable is left out of the current implementation of the PIE. This omission is considered acceptable since the variable had the second lowest relative weight in the original implementation in Portland (Singleton et al., 2014).

\subsection{Transit access}

Transit access is computed as the frequency of service for each stop during morning, midday and evening peak hours, as encoded in the GTFS datasets.

\subsection{Urban Living Infrastructure}

Information relative to the Urban Living Infrastructure variable comes from the business locations dataset. Business records which correspond to the targeted North American Industry Classification System (NAICS) codes (see Singleton et al., 2014 for details) are extracted from the database. The points are not weighted since every record is associated with a single geographical point. Restaurants, grocery stores, women's clothing stores and daycares are the most frequent categories, amounting for respectively $37 \%, 12 \%, 11 \%$ and $7 \%$ of targeted businesses. Gyms, bars, dry cleaners and bakeries count for another $13 \%$ of targeted businesses. The remaining $20 \%$ are split among the other 13 NAICS codes.

\subsubsection{Spatial unit}

The PIE is a grid-based measure, computed on a grid of $80 \mathrm{~m}$ by $80 \mathrm{~m}$ ( $264 \mathrm{ft}$. by $264 \mathrm{ft}$.) cells called Pedestrian Analysis Zones (PAZ). These dimensions correspond to the distance than can be covered by foot within one minute. The grid spans the extent of the GMA, minus water bodies. 


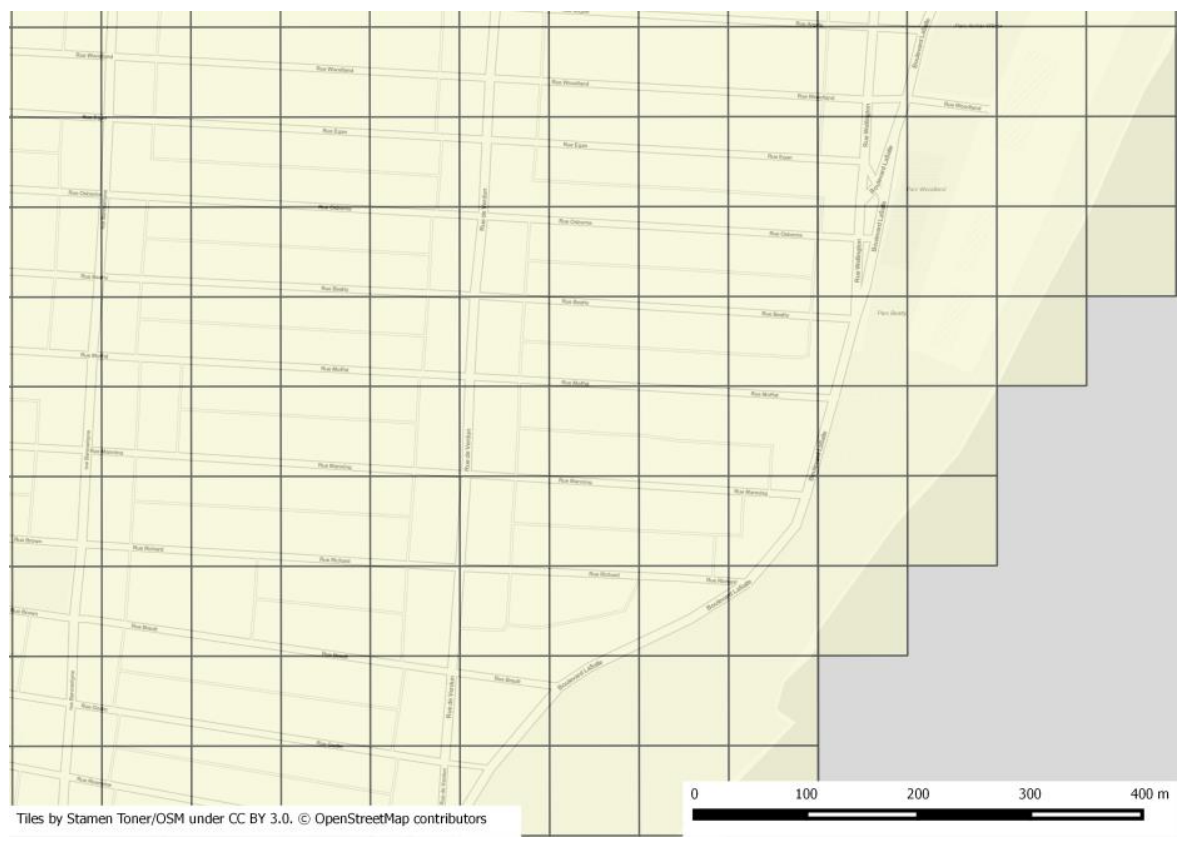

Figure 1: Close-up of the PAZ grid

\subsubsection{Kernel density}

In order to represent the decreasing attractivity of opportunities in the neighborhood as the distance increases from the measurement point, a kernel density algorithm is used to compute the variables. The decay function used is a quartic function, as shown in Figure 2, with the centroid of the PAZ used as the measurement point.

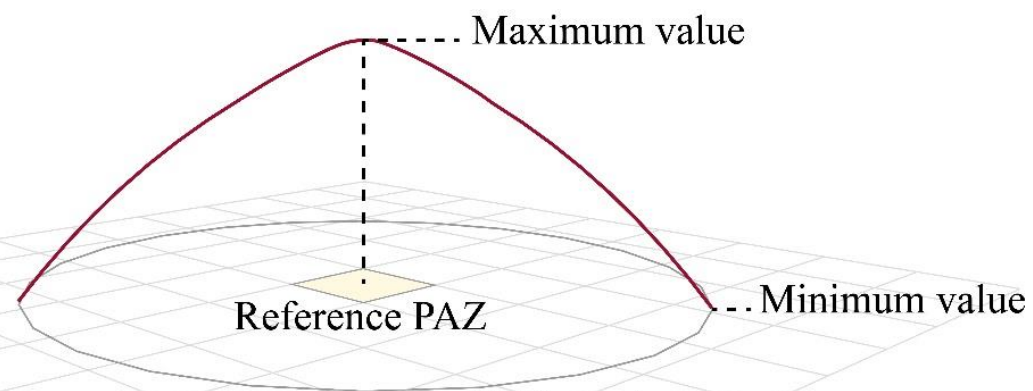

Catchment area

Figure 2 : Illustration of the kernel density calculation for a PAZ

11

12

13

14

15

16

A point layer of the relevant dataset for each variable - except People per $\mathrm{km}^{2}$ as explained earlier - is supplied to the Kernel Density algorithm included in the SAGA 2.1.2 Toolbox in QGIS 2.10.1. For polygon layers, object centroids are used as inputs for the kernel density algorithm. Each point is given a weight based on the variable value, as shown in Table 2. 
Table 2: Description of the variables used as inputs for the kernel density calculation

\begin{tabular}{|c|c|c|c|c|c|c|c|c|}
\hline Variable & $\mathbf{N}$ & Weight & $\begin{array}{l}\text { Search } \\
\text { Radius }\end{array}$ & Mean & Median & SD & Min & $\operatorname{Max}$ \\
\hline $\begin{array}{l}\text { Comfortable } \\
\text { facilities }\end{array}$ & $\begin{array}{l}59,673 \\
\text { segments }\end{array}$ & $\begin{array}{l}\begin{array}{l}\text { Length } \\
(\mathrm{m})\end{array} \\
\text { comfort }\end{array}$ & $\begin{array}{r}1600 \mathrm{~m} \\
(1 \mathrm{mi})\end{array}$ & 305.63 & 157.28 & 520.73 & 1.01 & $17,586.45$ \\
\hline Block size & $\begin{array}{l}36,433 \\
\text { blocks }\end{array}$ & Area $\left(m^{2}\right)$ & $\begin{array}{r}400 \mathrm{~m} \\
(0.25 \mathrm{mi})\end{array}$ & $90,982.36$ & $11,031.76$ & $902,953.55$ & 251.54 & $73,242,649.00$ \\
\hline $\begin{array}{l}\text { People per } \\
\mathbf{k m}^{2}\end{array}$ & $\begin{array}{l}897 \\
\text { census } \\
\text { tracts }\end{array}$ & $\begin{array}{l}\text { (People }+ \\
\text { jobs) } / \mathrm{km}^{2}\end{array}$ & $\begin{array}{r}400 \mathrm{~m} \\
(0.25 \mathrm{mi})\end{array}$ & $8,305.91$ & $5,303.50$ & $9,468.40$ & 9.67 & $135,567.85$ \\
\hline $\begin{array}{l}\text { Transit } \\
\text { access }\end{array}$ & $\begin{array}{l}17,806 \\
\text { stops }\end{array}$ & $\begin{array}{l}\text { Peak } \\
\text { frequency } \\
\text { (stop- } \\
\text { times) }\end{array}$ & $\begin{array}{r}400 \mathrm{~m} \\
(0.25 \mathrm{mi})\end{array}$ & 62.46 & 40.00 & 63.93 & 0.00 & $1,520.00$ \\
\hline $\begin{array}{l}\text { Urban Living } \\
\text { Infrastructur } \\
\text { e }\end{array}$ & $\begin{array}{l}18,575 \\
\text { amenities }\end{array}$ & $\mathrm{n} / \mathrm{a}$ * & $\begin{array}{r}400 \mathrm{~m} \\
(0.25 \mathrm{mi})\end{array}$ & $\mathrm{n} / \mathrm{a}$ & $\mathrm{n} / \mathrm{a}$ & $\mathrm{n} / \mathrm{a}$ & $\mathrm{n} / \mathrm{a}$ & $\mathrm{n} / \mathrm{a}$ \\
\hline
\end{tabular}

\subsubsection{Classification}

For each variable $(i)$, the observations are reclassified in five classes according to natural breaks in the data using the Jenks algorithm in R's ClassInt package (Bivand, 2015). Each observation is then given a score from 1 to $5\left(S_{i}\right)$ based on its class.

\subsubsection{Calculation of weights}

In order to weigh the importance of each variable inside the PIE, single-variable binary logit models are estimated, with the choice between walking and taking another mode of transportation as the dependent variable and each PIE variable, successively, as the explanatory variable. This modelling is carried out on a random subsample of $30 \%$ of the trip database, which is then discarded for the rest of the process.

\subsubsection{Calculation of the PIE score}

The coefficient $(\beta)$ associated to each PIE variable $(i)$ in the corresponding model is then used as the weight of that variable in the PIE itself. A normalization coefficient $(k)$ is used to bring the score on a scale from 20 to 100 when summing the 1-to-5 scores $\left(S_{i}\right)$. The formula for calculating each grid cell's PIE score is presented below.

$$
P I E=\sum_{i=1}^{5} k \times \beta_{i} \times S_{i}
$$

\subsection{Mode choice modelling}

A series of discrete choice models are estimated at the trip level to better understand the relation between the PIE and the choice to walk. Binary Logit models are used, with the two outcomes being 1) walking or 2) using any other mode of transportation. Models are estimated for different subsets of the dataset to study the variability of their predictive capacity according to the cutoff point used to define "short trips" as well as the trip purpose. 
Out of the 4,323,542 weighted trips in the Origin-Destination database, 474,846 trips were accomplished by foot, which amounts to a modal share of $10.96 \%$. This aggregate statistic masks the fact that walking cannot compete with motorized transportation for long distances. Indeed, over $90 \%$ of walk trips occur when the network distance between origin and destination is shorter than $3 \mathrm{~km}(1.86 \mathrm{mi})$. As shown in Figure 3, walking is preponderant for trips shorter than $700 \mathrm{~m}(0.43 \mathrm{mi})$ and is chosen for over $75 \%$ of very short trips of less than $300 \mathrm{~m}(0.19 \mathrm{mi})$. As trips get longer, the modal share of motorized modes increases rapidly. Precision of mode choice prediction models would then increase, but this would only be due to the growing number of negative observations (i.e. non-walking trips). Four subsamples are thus extracted, based on the maximum network length of the trip:

- $1.3 \mathrm{~km}(0.81 \mathrm{mi})$ - accounts for $80 \%$ of walk trips (see Morency et al., 2014)

- $1.6 \mathrm{~km}(0.93 \mathrm{mi})$ - accounts for $85 \%$ of walk trips

- $2 \mathrm{~km} \quad(1.24 \mathrm{mi})$ - accounts for $90 \%$ of walk trips

- $3 \mathrm{~km} \quad(1.86 \mathrm{mi})$ - accounts for $95 \%$ of walk trips

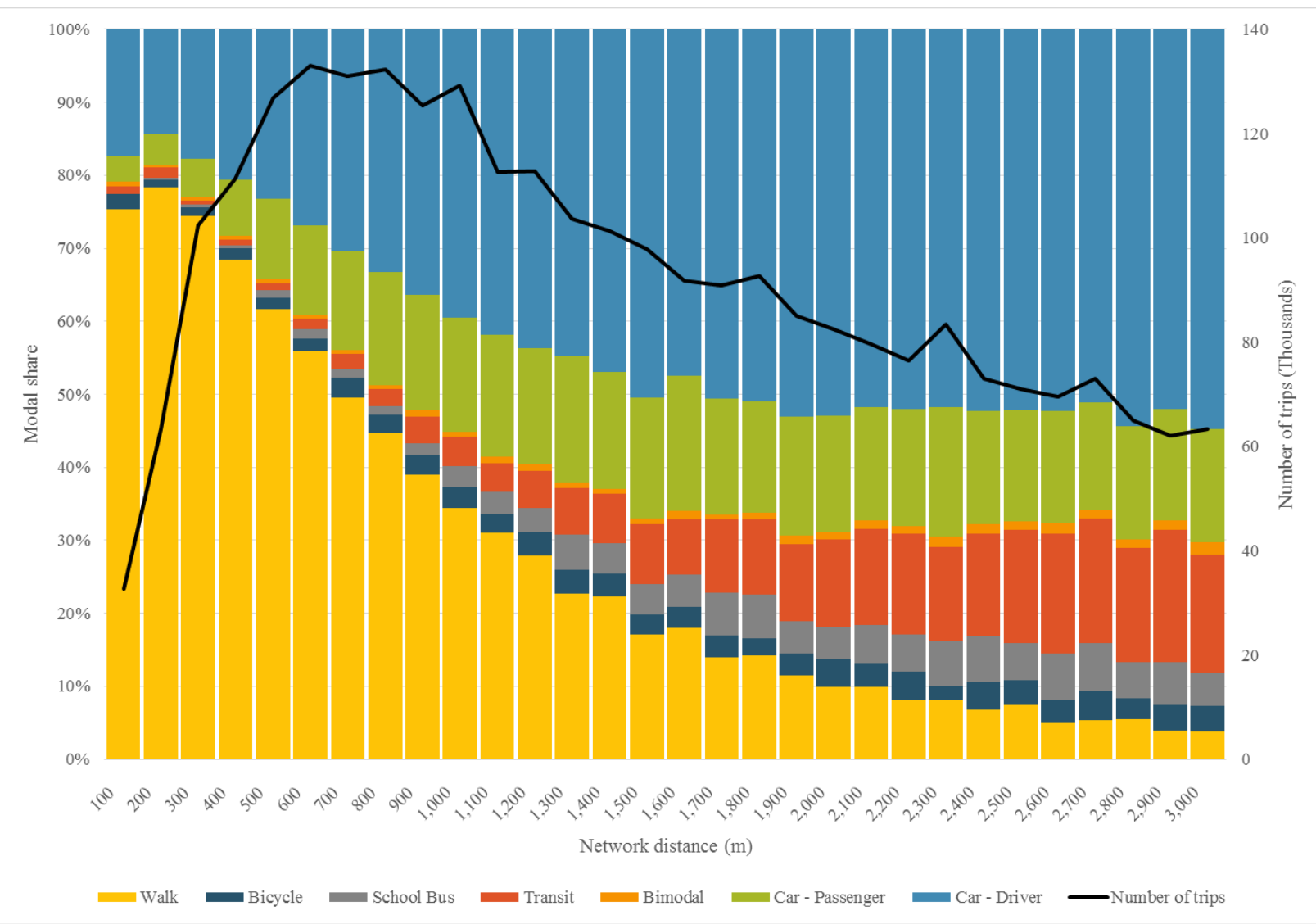

Figure 3: Modal share according to the length of the trip

The models are estimated on a subset equivalent to $40 \%$ of the initial dataset (before removing the first $30 \%$ for PIE weighing purposes). The remaining $30 \%$ are used for validation purposes. The PIE is inputted as a continuous explanatory variable, along with a number of 
1 into dummy variables beforehand to account for the non-linear effect of certain continuous 2 variables on the choice of walking.

3 Table 3: Variables used in choice models - Trips of less than $3 \mathrm{~km}(1.86 \mathrm{mi})(\mathrm{N}=47,875)$

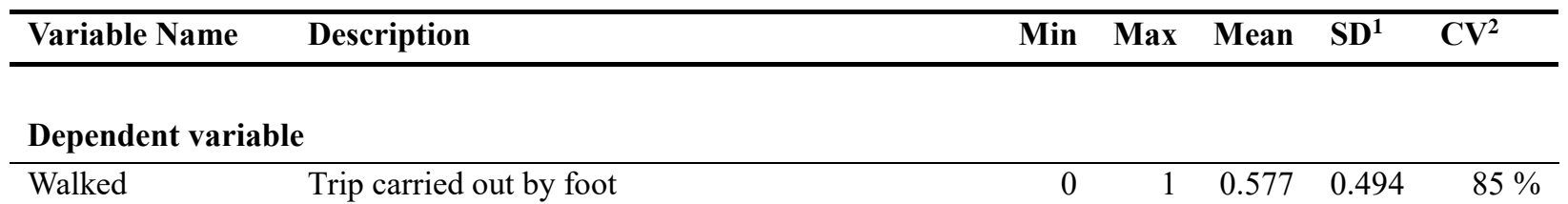

Household-related variables

\begin{tabular}{lllllll}
\hline Hhsize1 & Household size - 1 person & 0 & 1 & 0.129 & 0.335 & $260 \%$ \\
CarAccess0 & Access to a car - None & 0 & 1 & 0.138 & 0.345 & $250 \%$ \\
CarAccess0_1 & Access to a car - Less than 1 car/person (shared) & 0 & 1 & 0.253 & 0.435 & $172 \%$ \\
Reg3 & Region of residence - Eastern Montréal & 0 & 1 & 0.084 & 0.277 & $331 \%$ \\
Reg4 & Region of residence - Western Montréal & 0 & 1 & 0.115 & 0.319 & $277 \%$ \\
Reg5 & Region of residence - Longueuil Area & 0 & 1 & 0.098 & 0.297 & $304 \%$ \\
Reg6 & Region of residence - Laval & 0 & 1 & 0.074 & 0.262 & $354 \%$ \\
Reg7 & Region of residence - North Shore & 0 & 1 & 0.126 & 0.332 & $264 \%$ \\
Reg8 & Region of residence - South Shore & 0 & 1 & 0.112 & 0.316 & $281 \%$
\end{tabular}

Individual-related variables

$\begin{array}{llllllr}\text { GenderF } & \text { Gender }- \text { Female } & 0 & 1 & 0.549 & 0.498 & 91 \% \\ \text { Age5_15 } & \text { Age }- \text { Between 5 and 15 years old } & 0 & 1 & 0.204 & 0.403 & 198 \% \\ \text { Age16_24 } & \text { Age }- \text { Between 16 and 24 years old } & 0 & 1 & 0.068 & 0.252 & 369 \% \\ \text { Age65+ } & \text { Age }- \text { Over 64 years old } & 0 & 1 & 0.172 & 0.377 & 220 \%\end{array}$

Trip-related variables

\begin{tabular}{|c|c|c|c|c|c|c|}
\hline PurposeShop & Trip purpose - Shopping & 0 & 1 & 0.239 & 0.426 & $179 \%$ \\
\hline PurposeLeisure & Trip purpose - Leisure & 0 & 1 & 0.120 & 0.325 & $271 \%$ \\
\hline PurposePickup & Trip purpose - Picking up or dropping off someone & 0 & 1 & 0.189 & 0.392 & $207 \%$ \\
\hline NetDist200- & Length of trip on network - Shorter than $200 \mathrm{~m}$ & 0 & 1 & 0.039 & 0.193 & $498 \%$ \\
\hline NetDist200_400m & Length of trip on network $-200 \mathrm{~m}$ to $400 \mathrm{~m}$ & 0 & 1 & 0.079 & 0.269 & $342 \%$ \\
\hline NetDist400_800 & Length of trip on network - $400 \mathrm{~m}$ to $800 \mathrm{~m}$ & 0 & 1 & 0.189 & 0.391 & $207 \%$ \\
\hline TripChComplex & Trip chaining - Complex & 0 & 1 & 0.691 & 0.462 & $67 \%$ \\
\hline Highway200m & Highway within $200 \mathrm{~m}$ & 0 & 1 & 0.053 & 0.224 & $422 \%$ \\
\hline PIE & Pedestrian Index of the Environment & 20 & 96 & 50.28 & 15.40 & $31 \%$ \\
\hline
\end{tabular}

As seen in Table 3, the models account for household size, access level to a car per licenseholder in the household, location of the residence, as well as the individual's gender and work status. The trip's purpose, network length and chaining are also taken into account. Some variables,

\footnotetext{
${ }^{1}$ Standard deviation $(\sigma)$

${ }^{2}$ Coefficient of variation $(\sigma / \mu)$
} 
like work status, as well as certain factor levels are dropped as a result of a preliminary correlation analysis. The presence of a highway in a $200 \mathrm{~m}(0.12 \mathrm{mi})$ radius of the trip's production end is included in every model, since it has proven statistically related to the choice of walking in the original PIE validation in the Portland region (Clifton et al., 2013). For each subset, two models are estimated: a base model with only the control variables and a model including the PIE. Validation of the model is carried out on a reconstructed population based on sampling expansion factors.

Additional models are estimated for trips of $1.3 \mathrm{~km}(0.81 \mathrm{mi})$ or less for trip purposebased subsets. The effect of the PIE is tested on four subsets: work trips, school trips, shopping trips and leisure trips. Purpose-based models control for car access, home location, network length and trip chaining.

\section{RESULTS}

\subsection{Active travel behavior in the GMA}

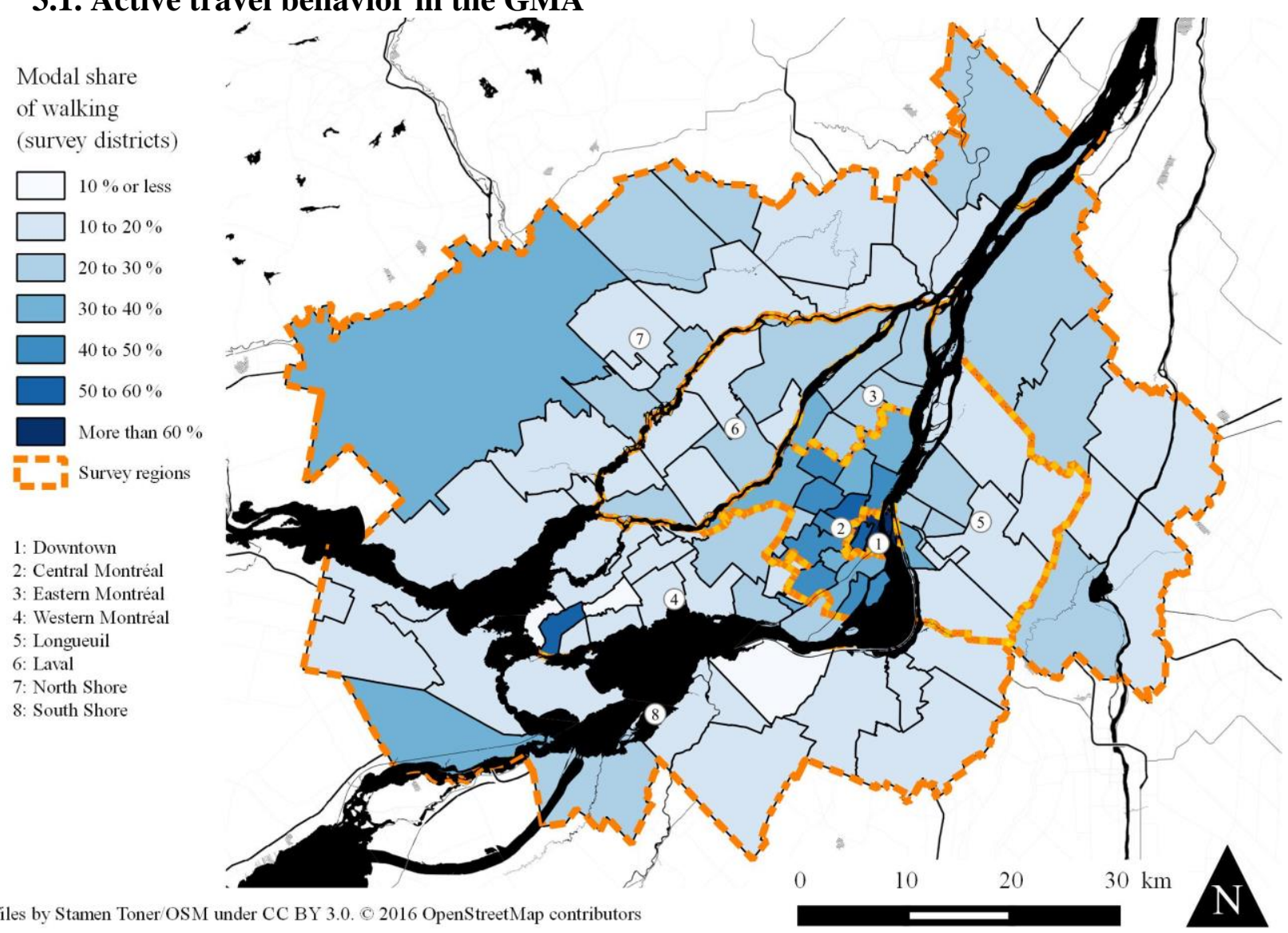

Tiles by Stamen Toner/OSM under CC BY 3.0. 02016 OpenStreetMap contributors

Figure 4: Modal share of walking per survey district for trips less than $3 \mathbf{k m}$

A look at the spatial distribution of the modal share of walking in the GMA, as depicted in Figure 4 , shows that the location of the production end of the trip has an impact on the choice of walking for short trips of less than $3 \mathrm{~km}$. The modal share of walking reaches $60 \%$ in parts of the Montréal region (\#2). The effect of distance to downtown - measured as the Euclidean distance 
from the trip production to the central business district (CBD) - is distorted, as the wealthier, more sprawled Western Montréal region (\#4) sees a globally lower modal share of walking than its counterpart Eastern Montréal (\#3) or eastern Laval (\#6).

\subsection{Transfer of the PIE}

Table 4 shows the weight assigned to each PIE variable, as obtained from the singlevariable binary logit models. People per $\mathrm{km}^{2}$ has the highest weight, almost twice the weight of the lowest weighted variable, Transit access. This is coherent with the original PIE implementation in the Portland area, with the notable exception of the Comfortable facilities variable. This variable had the lowest weight in Portland, whereas it obtains the second highest weight in the GMA. This can be explained by the very nature of the variable computation: the original measure used a classification of the road network relative to its comfort for cyclists, whereas the current 13 implementation uses a simple road hierarchy classification.

14 Table 4: Variable weights obtained from single-variable logit models

\begin{tabular}{lrrrr}
\hline Variable & Coefficient $(\boldsymbol{\beta})$ & $\begin{array}{l}\text { Scaled Weight } \\
(\boldsymbol{\beta} \times \mathbf{k})\end{array}$ & $\begin{array}{l}\text { Minimum Weighted } \\
\text { Value }\end{array}$ & \multicolumn{2}{l}{$\begin{array}{l}\text { Maximum Weighted } \\
\text { Value }\end{array}$} \\
\hline Comfortable facilities & 0.590 & 4.13 & 4.13 & 20.65 \\
Block size & 0.588 & 4.11 & 4.11 & 20.55 \\
People per km ${ }^{2}$ & 0.800 & 5.60 & 5.60 & 28.00 \\
Transit access & 0.417 & 2.92 & 2.92 & 14.60 \\
Urban Living & & 3.23 & 3.23 & 16.15 \\
Infrastructure & 0.462 & & $\mathbf{2 0}$ & $\mathbf{1 0 0}$ \\
\hline Total & & &
\end{tabular}

Figure 5 shows the spatial distribution of the PIE score in the GMA. The highest scores are located in the downtown area as well as in central neighborhoods, typically built before the 1950's and characterized by mixed-use commercial arteries and a dense residential environment. The lowest values, on the other hand, are located in industrial parks, agricultural zones and great parks. Most PAZ scores are between 40 and 60, which corresponds to a suburban or postwar urban environment. This typology is coherent with the results of the original implementation of the PIE in the Portland area (Singleton et al., 2014).

Figure 6 shows the modal share of short trips $-3 \mathrm{~km}(1.86 \mathrm{mi})$ or less - for each interval of 10 in the PIE score of the PAZ that contains the production end of the trip. The modal share of walk trips seems to increase when the PIE score does, although very high PIE values, between 90 and 100 , seem to be linked to a slight decrease in walk trips in favor of transit and driving. 


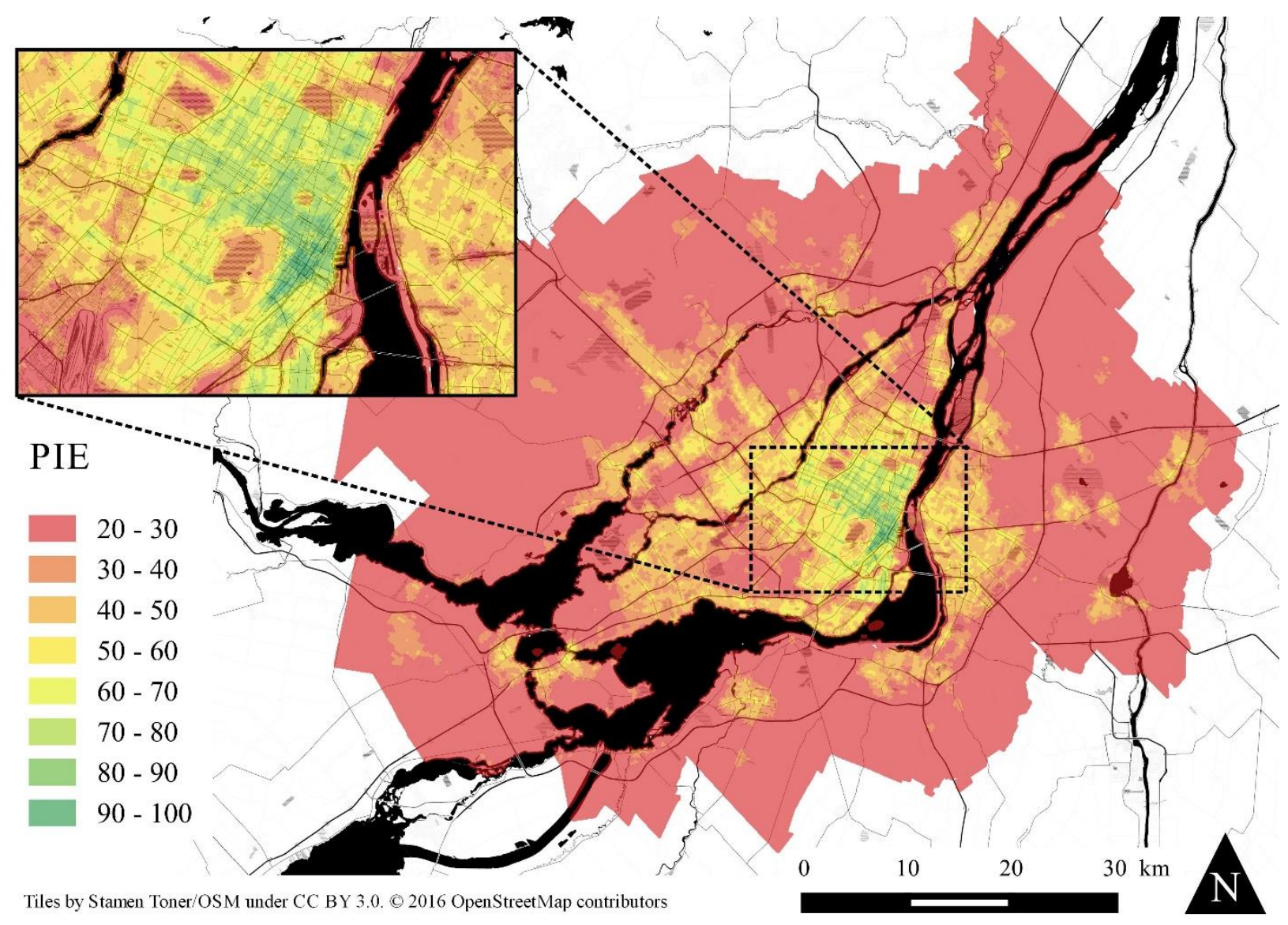

Figure 5: Spatial distribution of the PIE in the GMA
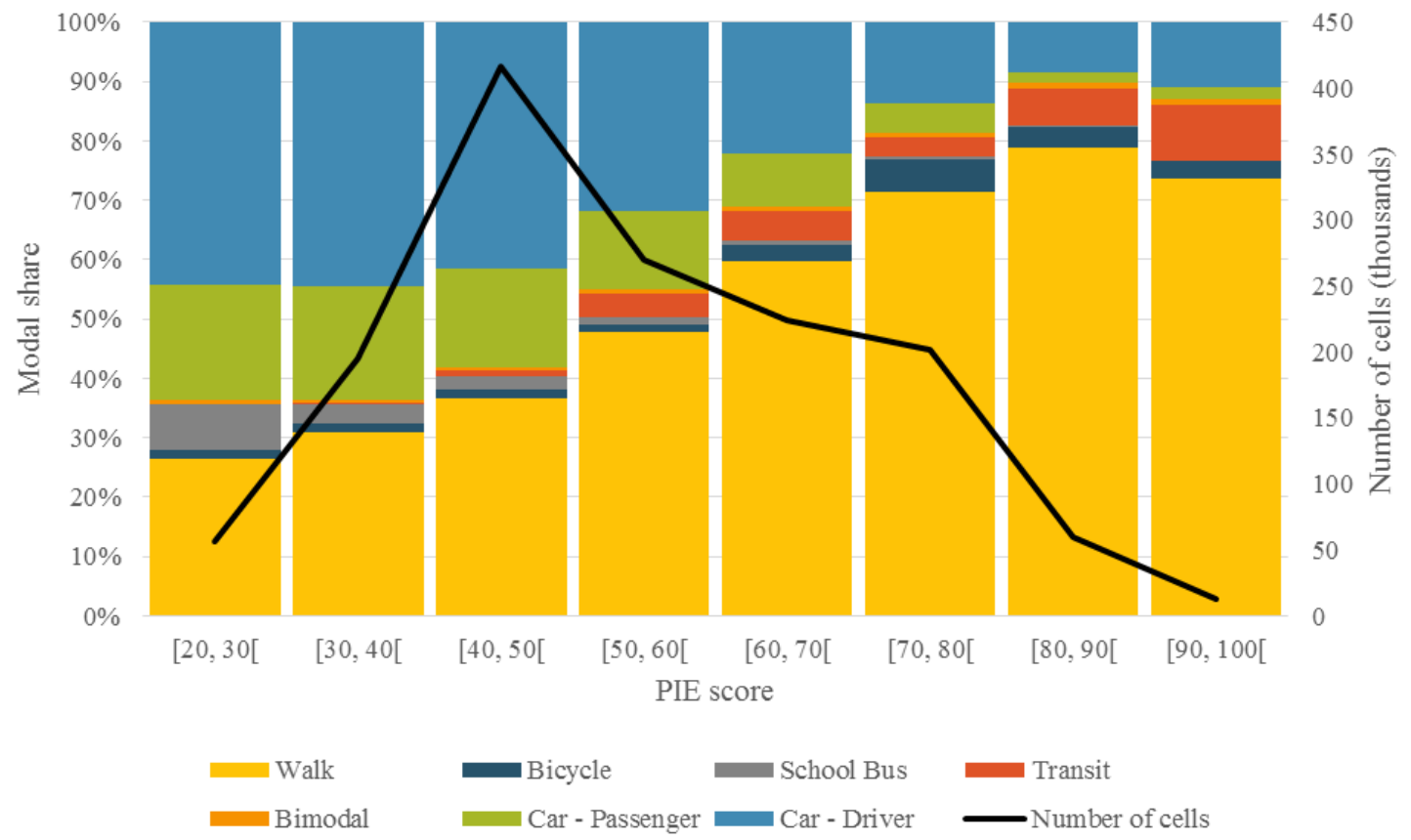

Figure 6: Modal share of short trips for each class of the PIE 


\subsection{Mode choice models - segmented by network trip distance}

Results from the modelling process based on trip distance subsets are shown in Table 5. All control variables are statistically significant, with the exception of smaller household size for shorter trips. Network length of the trip has the highest correlation with the choice of walking, a correlation that increases as longer trips are introduced in the mode choice model.

Inclusion of the PIE seems to slightly attenuate this correlation. Models that include the PIE also see a reduced correlation of the location of the household residence, which is coherent with the existence of high-PIE areas closer to downtown and low-PIE areas in the suburban zones of the GMA.

11 Table 5: Model results for based models, stratified by maximum length of trip - base models and with PIE

\begin{tabular}{|c|c|c|c|c|c|c|c|c|c|c|c|c|}
\hline & $1.3 \mathrm{~km}$ & & & & & & $1.6 \mathrm{~km}$ & & & & & \\
\hline & Base & & & PIE & & & Base & & & PIE & & \\
\hline & Coeff. $^{3}$ & $\mathrm{OR}^{4}$ & & Coeff. & OR & & Coeff. & OR & & Coeff. & OR & \\
\hline Intercept & -0.49 & 0.61 & $* * *$ & -2.04 & 0.13 & $* * *$ & -0.63 & 0.53 & $* * *$ & -2.30 & 0.10 & $* * *$ \\
\hline Hhsize1 & 0.11 & 1.12 & & 0.09 & 1.09 & & 0.12 & 1.13 & . & 0.09 & 1.09 & \\
\hline CarAccess 0 & 1.62 & 5.06 & $* * *$ & 1.55 & 4.72 & $* * *$ & 1.55 & 4.73 & $* * *$ & 1.48 & 4.40 & $* * *$ \\
\hline CarAccess0_1 & 0.30 & 1.35 & $* * *$ & 0.26 & 1.30 & $* * *$ & 0.31 & 1.37 & $* * *$ & 0.28 & 1.32 & $* * *$ \\
\hline Reg3 & -0.69 & 0.5 & $* * *$ & -0.37 & 0.69 & $* * *$ & -0.67 & 0.51 & $* * *$ & -0.31 & 0.73 & $* * *$ \\
\hline Reg4 & -0.87 & 0.42 & $* * *$ & -0.48 & 0.62 & $* * *$ & -0.97 & 0.38 & $* * *$ & -0.53 & 0.59 & $* * *$ \\
\hline Reg5 & -0.89 & 0.41 & $* * *$ & -0.46 & 0.63 & $* * *$ & -0.94 & 0.39 & $* * *$ & -0.48 & 0.62 & $* * *$ \\
\hline Reg6 & -1.27 & 0.28 & $* * *$ & -0.87 & 0.42 & $* * *$ & -1.31 & 0.27 & $* * *$ & -0.87 & 0.42 & $* * *$ \\
\hline Reg7 & -1.14 & 0.32 & $* * *$ & -0.49 & 0.61 & $* * *$ & -1.20 & 0.30 & $* * *$ & -0.49 & 0.61 & $* * *$ \\
\hline Reg8 & -1.11 & 0.33 & $* * *$ & -0.48 & 0.62 & $* * *$ & -1.08 & 0.34 & $* * *$ & -0.39 & 0.68 & $* * *$ \\
\hline GenderF & 0.12 & 1.13 & $* *$ & 0.13 & 1.14 & $* *$ & 0.16 & 1.17 & $* * *$ & 0.17 & 1.18 & $* * *$ \\
\hline Age5_15 & 0.63 & 1.87 & $* * *$ & 0.71 & 2.04 & $* * *$ & 0.53 & 1.70 & $* * *$ & 0.63 & 1.88 & $* * *$ \\
\hline Age16_24 & 0.73 & 2.08 & $* * *$ & 0.79 & 2.20 & $* * *$ & 0.61 & 1.84 & $* * *$ & 0.66 & 1.93 & $* * *$ \\
\hline Age65+ & -0.39 & 0.68 & $* * *$ & -0.34 & 0.71 & $* * *$ & -0.39 & 0.68 & $* * *$ & -0.33 & 0.72 & $* * *$ \\
\hline PurposeShop & -0.31 & 0.73 & $* * *$ & -0.31 & 0.73 & $* * *$ & -0.40 & 0.67 & $* * *$ & -0.39 & 0.68 & $* * *$ \\
\hline PurposeLeisure & -0.14 & 0.87 & . & -0.16 & 0.85 & * & -0.29 & 0.75 & $* * *$ & -0.30 & 0.74 & $* * *$ \\
\hline PurposePickup & -0.84 & 0.43 & $* * *$ & -0.76 & 0.47 & $* * *$ & -0.82 & 0.44 & $* * *$ & -0.73 & 0.48 & $* * *$ \\
\hline NetDist200- & 2.12 & 8.29 & $* * *$ & 2.09 & 8.06 & $* * *$ & 2.31 & 10.07 & $* * *$ & 2.28 & 9.79 & $* * *$ \\
\hline NetDist200_400m & 1.71 & 5.53 & $* * *$ & 1.69 & 5.42 & $* * *$ & 1.87 & 6.47 & $* * *$ & 1.84 & 6.31 & $* * *$ \\
\hline NetDist400_800 & 0.90 & 2.45 & $* * *$ & 0.88 & 2.40 & $* * *$ & 1.13 & 3.11 & $* * *$ & 1.11 & 3.02 & $* * *$ \\
\hline TripChComplex & -0.21 & 0.81 & $* * *$ & -0.25 & 0.78 & $* * *$ & -0.22 & 0.80 & $* * *$ & -0.27 & 0.76 & $* * *$ \\
\hline Highway200m & -0.40 & 0.67 & $* * *$ & -0.36 & 0.70 & $* * *$ & -0.30 & 0.74 & $* * *$ & -0.27 & 0.76 & $* *$ \\
\hline PIE & - & - & & 0.02 & 1.02 & $* * *$ & - & - & & 0.03 & 1.03 & $* * *$ \\
\hline
\end{tabular}

${ }^{3}$ Coefficient

${ }^{4}$ Odds ratio 


\begin{tabular}{|c|c|c|c|c|c|c|c|c|c|c|c|c|}
\hline & \multicolumn{6}{|l|}{$2 \mathrm{~km}$} & \multicolumn{6}{|l|}{$3 \mathrm{~km}$} \\
\hline & \multicolumn{3}{|l|}{ Base } & \multicolumn{3}{|l|}{ PIE } & \multicolumn{3}{|l|}{ Base } & \multicolumn{3}{|l|}{ PIE } \\
\hline & Coeff. & OR & & Coeff. & OR & & Coeff. & OR & & Coeff. & OR & \\
\hline Intercept & -0.87 & 0.42 & $* * *$ & -2.53 & 0.08 & $* * *$ & -1.43 & 0.24 & $* * *$ & -3.22 & 0.04 & $* * *$ \\
\hline Hhsize1 & 0.17 & 1.18 & $* *$ & 0.13 & 1.14 & $*$ & 0.22 & 1.25 & $* * *$ & 0.19 & 1.21 & $* * *$ \\
\hline CarAccess0 & 1.37 & 3.92 & $* * *$ & 1.29 & 3.62 & $* * *$ & 1.32 & 3.73 & $* * *$ & 1.22 & 3.40 & $* * *$ \\
\hline CarAccess0_1 & 0.31 & 1.37 & $* * *$ & 0.29 & 1.33 & $* * *$ & 0.36 & 1.44 & $* * *$ & 0.34 & 1.40 & $* * *$ \\
\hline Reg3 & -0.69 & 0.50 & $* * *$ & -0.34 & 0.71 & $* * *$ & -0.62 & 0.54 & $* * *$ & -0.24 & 0.79 & $* * *$ \\
\hline Reg4 & -0.89 & 0.41 & $* * *$ & -0.45 & 0.64 & $* * *$ & -0.94 & 0.39 & $* * *$ & -0.46 & 0.63 & $* * *$ \\
\hline Reg5 & -0.92 & 0.40 & $* * *$ & -0.45 & 0.64 & $* * *$ & -0.87 & 0.42 & $* * *$ & -0.37 & 0.69 & $* * *$ \\
\hline Reg6 & -1.24 & 0.29 & $* * *$ & -0.82 & 0.44 & $* * *$ & -1.14 & 0.32 & $* * *$ & -0.67 & 0.51 & $* * *$ \\
\hline Reg7 & -1.20 & 0.30 & $* * *$ & -0.53 & 0.59 & $* * *$ & -1.11 & 0.33 & $* * *$ & -0.37 & 0.69 & $* * *$ \\
\hline Reg8 & -1.08 & 0.34 & $* * *$ & -0.40 & 0.67 & $* * *$ & -0.97 & 0.38 & $* * *$ & -0.25 & 0.78 & $* * *$ \\
\hline GenderF & 0.14 & 1.15 & $* * *$ & 0.15 & 1.16 & $* * *$ & 0.10 & 1.11 & $* *$ & 0.11 & 1.12 & $* * *$ \\
\hline Age5_15 & 0.50 & 1.65 & $* * *$ & 0.59 & 1.81 & $* * *$ & 0.64 & 1.89 & $* * *$ & 0.73 & 2.08 & $* * *$ \\
\hline Age16_24 & 0.73 & 2.08 & $* * *$ & 0.78 & 2.19 & $* * *$ & 0.62 & 1.85 & $* * *$ & 0.67 & 1.96 & $* * *$ \\
\hline Age65+ & -0.40 & 0.67 & $* * *$ & -0.36 & 0.70 & $* * *$ & -0.33 & 0.72 & $* * *$ & -0.26 & 0.77 & $* * *$ \\
\hline PurposeShop & -0.36 & 0.70 & $* * *$ & -0.34 & 0.71 & $* * *$ & -0.34 & 0.71 & $* * *$ & -0.31 & 0.73 & $* * *$ \\
\hline PurposeLeisure & -0.15 & 0.86 & * & -0.17 & 0.84 & $* *$ & -0.11 & 0.90 & . & -0.13 & 0.88 & $*$ \\
\hline PurposePickup & -0.76 & 0.47 & $* * *$ & -0.67 & 0.51 & $* * *$ & -0.78 & 0.46 & $* * *$ & -0.69 & 0.50 & $* * *$ \\
\hline NetDist200- & 2.48 & 11.89 & $* * *$ & 2.44 & 11.44 & $* * *$ & 2.87 & 17.55 & $* * *$ & 2.83 & 16.98 & $* * *$ \\
\hline NetDist200_400m & 2.15 & 8.61 & $* * *$ & 2.13 & 8.45 & $* * *$ & 2.52 & 12.43 & $* * *$ & 2.50 & 12.13 & $* * *$ \\
\hline NetDist400_800 & 1.37 & 3.95 & $* * *$ & 1.34 & 3.83 & $* * *$ & 1.81 & 6.09 & $* * *$ & 1.77 & 5.90 & $* * *$ \\
\hline TripChComplex & -0.29 & 0.75 & $* * *$ & -0.33 & 0.72 & $* * *$ & -0.20 & 0.82 & $* * *$ & -0.25 & 0.78 & $* * *$ \\
\hline Highway $200 \mathrm{~m}$ & -0.19 & 0.83 & * & -0.16 & 0.85 & * & -0.17 & 0.84 & $*$ & -0.17 & 0.84 & * \\
\hline PIE & - & - & & 0.03 & 1.03 & $* * *$ & - & - & & 0.03 & 1.03 & $* * *$ \\
\hline
\end{tabular}

As for the PIE itself, it is significantly correlated with the choice of walking for short trips. In every model, the PIE's odds ratio is between 1.02 and 1.03 , which indicates that an improvement of 1 in the PIE score (on its native scale of 20 to 100) is correlated with an increase of the odds of choosing walking by 2 to $3 \%$. While the effect seems minimal, this is due to the measure's native scale, where a 1-unit increase represent a small change that might not be perceived by an individual. A 10-unit increase, on the other hand, has been identified as a perceivable step: low-density suburban neighborhoods to suburban shopping districts, for example (Singleton et al., 2014). Given the logit model's linear-in-parameters specification and using the predictor's coefficient $\beta$, one can compute the odds ratio for an increase from $x$ to $x^{\prime}$ in a continuous predictor:

$$
e^{\beta x^{\prime}} / e^{\beta x}=e^{\beta\left(x^{\prime}-x\right)} .
$$


1 Table 6: Model fit and validation statistics - models stratified by maximum length of trip

\begin{tabular}{lcccccccc}
\hline \multirow{2}{*}{ Model } & $\mathbf{1 . 3} \mathbf{~ k m}$ & \multicolumn{3}{c}{$\mathbf{1 . 6} \mathbf{~ k m}$} & \multicolumn{2}{c}{$\mathbf{~ k m}$} & \multicolumn{3}{c}{$\mathbf{3 ~ k m}$} & PIE \\
\cline { 2 - 8 } & $\mathbf{B a s e}$ & $\mathbf{P I E}$ & Base & PIE & Base & PIE & Base & P \\
\hline N (reconstructed N) & $10,583(232,972)$ & $12,739(282,628)$ & $15,308(337,922)$ & $20,517(454,014)$ \\
McFadden (pR $\left.{ }^{2}\right)$ & 0.216 & 0.223 & 0.232 & 0.240 & 0.237 & 0.245 & 0.265 & 0.273 \\
Accuracy & 0.642 & 0.647 & 0.652 & 0.656 & 0.674 & 0.678 & 0.716 & 0.719 \\
Sensitivity & 0.614 & 0.620 & 0.579 & 0.584 & 0.552 & 0.556 & 0.502 & 0.507 \\
Specificity & 0.667 & 0.671 & 0.705 & 0.709 & 0.745 & 0.748 & 0.803 & 0.805 \\
Kappa & 0.281 & 0.291 & 0.284 & 0.294 & 0.298 & 0.305 & 0.306 & 0.313 \\
AIC & 15314 & 15183 & 17728 & 17539 & 20430 & 20228 & 24064 & 23805 \\
\hline
\end{tabular}

3

4 Including the PIE in mode choice models also helps model fit as well as mode choice prediction 5 accuracy. 
1 Table 7 shows that McFadden's $\mathrm{R}^{2}$ increases and AIC decreases when compared to the base 2 model, indicating a better model fit. 
1 Table 7 also shows statistics from the validation step. Adding the PIE to the mode choice 2 model increases not only global accuracy, but sensitivity (true positive rate) and specificity (true 3 negative rate) as well, albeit slightly. The models' Kappa statistic increases as well with the PIE, 4 indicating that the agreement between the observed values and the predicted ones is less likely to 5 be attributable to chance. The Kappa statistics are still in the lower range, with none over 0.4.

\subsection{Mode choice models - stratified by trip purpose}


Table 7 shows the odds ratios from the purpose-specific models. All models include the PIE and are based on the smallest trip subset $(<1.3 \mathrm{~km}$ trip distance). Car access and trip distance have a consistent high correlation with walking behavior across trip purposes, just like in the previous models. Odds ratios for the PIE vary from 1.02 for school trips to 1.05 for leisure trips.

5 This suggests that school trips are less elastic than other trips as far as the PIE is concerned, as 6 shown in Figure 7.

Model results are consistent with findings in the original PIE application in the Portland 8 area. The 1.04 odds ratio of the PIE for work trips in the GMA is the same as the odds ratio for 9 home-based work trips in Portland (Clifton et al., 2013). 
Table 7: Model results for models including the PIE, stratified by purpose

\begin{tabular}{|c|c|c|c|c|c|c|c|c|c|c|c|c|}
\hline \multirow[t]{2}{*}{ Model } & \multicolumn{3}{|l|}{ Work } & \multicolumn{3}{|l|}{ School } & \multicolumn{3}{|c|}{ Shopping } & \multicolumn{3}{|c|}{ Leisure } \\
\hline & Coef. & $\overline{\text { OR }}$ & & Coef. & OR & & Coef. & $\overline{\text { OR }}$ & & Coef. & $\overline{\text { OR }}$ & \\
\hline Intercept & -3.22 & 0.04 & $* * *$ & -1.27 & 0.28 & $* * *$ & -3.51 & 0.03 & $* * *$ & -4.61 & 0.01 & $* * *$ \\
\hline Hhsize1 & 0.08 & 1.08 & & -0.63 & 0.53 & & -0.19 & 0.83 & & 0.05 & 1.05 & \\
\hline Hhsize4+ & -0.13 & 0.88 & & -0.07 & 0.93 & & - & - & & -0.05 & 0.95 & \\
\hline CarAccess 0 & 1.82 & 6.18 & $* * *$ & 1.24 & 3.46 & $* * *$ & 1.20 & 3.31 & $* * *$ & 1.92 & 6.81 & $* * *$ \\
\hline CarAccess $0 \_1$ & 0.68 & 1.98 & $* * *$ & 0.19 & 1.21 & . & 0.21 & 1.23 & & 0.50 & 1.65 & $* * *$ \\
\hline Reg3 & -0.30 & 0.74 & & -0.21 & 0.81 & & -0.48 & 0.62 & . & 0.19 & 1.21 & \\
\hline Reg4 & -0.02 & 0.98 & & -0.04 & 0.96 & & -0.58 & 0.56 & $*$ & -0.27 & 0.76 & \\
\hline Reg5 & -0.33 & 0.72 & & -0.29 & 0.75 & $*$ & -0.56 & 0.57 & $*$ & -0.20 & 0.82 & \\
\hline Reg6 & -0.20 & 0.82 & & -0.62 & 0.54 & $* * *$ & -1.02 & 0.36 & $* * *$ & -0.05 & 0.95 & \\
\hline Reg7 & -0.13 & 0.88 & & 0.08 & 1.08 & & -0.48 & 0.62 & . & -0.56 & 0.57 & $*$ \\
\hline Reg8 & -0.05 & 0.95 & & 0.05 & 1.05 & & -0.54 & 0.58 & . & 0.22 & 1.25 & * \\
\hline GenderF & 0.49 & 1.64 & $* * *$ & 2.09 & 8.06 & $* * *$ & 0.16 & 1.17 & & 2.36 & 10.58 & $* * *$ \\
\hline NetDist200- & 1.75 & 5.77 & $* * *$ & 1.72 & 5.59 & $* * *$ & 2.22 & 9.22 & $* * *$ & 1.70 & 5.46 & $* * *$ \\
\hline NetDist200_400m & 1.65 & 5.20 & $* * *$ & 0.86 & 2.36 & $* * *$ & 1.96 & 7.09 & $* * *$ & 0.88 & 2.40 & $* * *$ \\
\hline NetDist400_800 & 0.85 & 2.35 & $* * *$ & 0.47 & 1.60 & $* * *$ & 0.98 & 2.67 & $* * *$ & -0.20 & 0.82 & . \\
\hline IsNHB & -1.35 & 0.26 & $* * *$ & - & - & & -0.48 & 0.62 & $* * *$ & -1.02 & 0.36 & $* * *$ \\
\hline Highway $200 \mathrm{~m}$ & 0.02 & 1.02 & & -0.33 & 0.72 & & 0.48 & 1.62 & & 0.31 & 1.37 & \\
\hline PIE & 0.04 & 1.04 & $* * *$ & 0.02 & 1.02 & $* * *$ & 0.04 & 1.04 & $* * *$ & 0.05 & 1.05 & $* * *$ \\
\hline
\end{tabular}

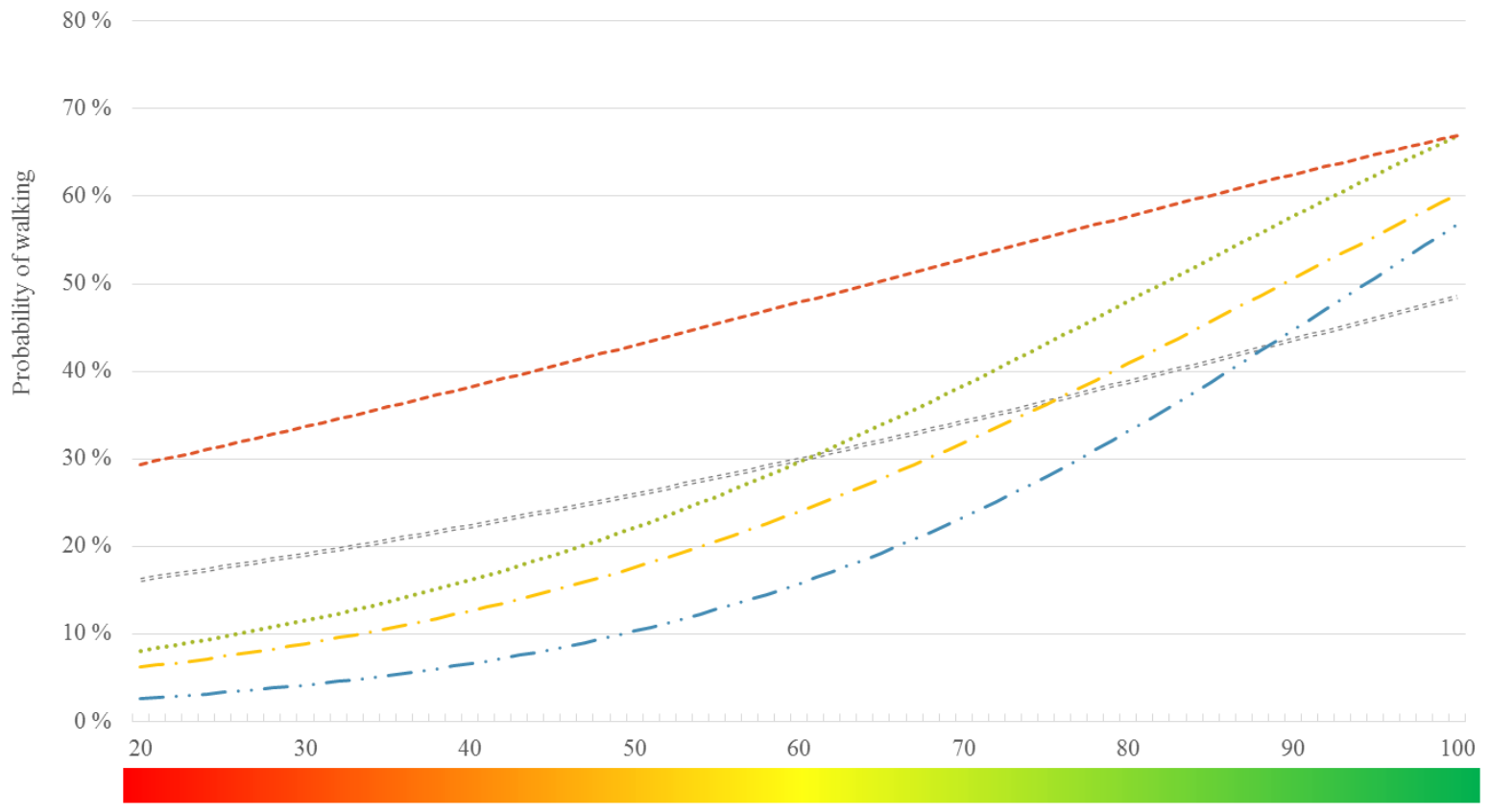

PIE value 


\section{DISCUSSION}

A composite measure of the urban form, the Pedestrian Index of the Environment (PIE), developed in Portland, Oregon, was applied to a new metropolitan area to assess its spatial transferability. The PIE covers the 5 D's of urban form, as described by Ewing and Cervero (Ewing and Cervero, 2010), and uses a decay function-based algorithm as well as modelling-based variable weighing. The combination of these strengths makes the PIE a unique measure in the walkability literature (Vale et al., 2015; Wong et al., 2011). Despite these promising characteristics, the PIE, while correlated with walking behavior in Portland (Clifton et al., 2016a, b; Clifton et al., 2013), had never been tested outside its native area. This paper provides an application of the measure at the metropolitan scale and disaggregated trip data from a large-scale transportation survey.

\subsection{Transfer}

This paper demonstrated the practical transfer of the PIE using entirely different local data sources. Because the original PIE was constructed using data specific to Portland, it was impossible to transfer it directly to another metropolitan area. The databases and GIS tools available enabled the transfer of the PIE to the GMA with the use of mostly open or public datasets and open source tools.

The resulting measure proved similar to the original implementation of the PIE in its capacity to describe urban environments. The same score in Portland and in Montréal describes similar types of neighborhoods and the internal weighing of the different variables is comparable.

The observed link between PIE score and walking behavior through descriptive analysis supports the idea of the PIE's transferability to the GMA. Inclusion of the PIE in mode choice models improved their global accuracy as well as their sensitivity, significance and AIC, which confirms that the PIE is an efficient tool for representing the urban form in mode choice modelling applications.

Although a variable, Sidewalk density, was omitted due to insufficient data at the metropolitan scale, the measure still proved useful in representing the urban form as it relates to walking behavior. Further research in other urban contexts where such data is available could confirm the role of sidewalk presence in such a measure.

In short, the process described in the Methods section of this paper can be used to create a PIE dataset for use in other metropolitan areas beyond Portland and Montréal. This is an important methodological step towards the wider use of the PIE in walkability research.

\subsection{Transferability}

Once the PIE has been transferred to the GMA, its association with walking behavior is significant and appears roughly similar across space. The PIE was found to be significantly and positively correlated to the choice of walking for short trips of less than $3 \mathrm{~km}(1.86 \mathrm{mi})$ and for shorter distance subsets. Analyses on samples segmented by trip purpose showed that the PIE was more strongly correlated to the choice of walking for work, leisure or shopping in very short trips. This highlights the importance of the relationship between the urban form and mode choice for unconstrained trips, but also for the more constrained commuting trips.

Purpose-based modelling also enabled a comparison between the correlations found in Portland and in Montréal between the PIE and walking behavior. This comparison shows that the PIE's ability to represent the walking environment is constant in two different metropolitan areas of different size and with distinct mobility patterns. Although more research is needed, this finding suggests that people's behavioral sensitivity to pedestrian-relevant aspects of the urban form may 
be more universal (at least in a North American context) than region-specific. This is an important empirical finding that should be examined in other urban areas.

\subsection{Limitations}

Some limitations to this paper must be mentioned. First, the use of cross-sectional datasets means that no conclusions can be drawn as to the causality between the structure urban environment, as represented by the PIE, and the choice to walk for short trips. Moreover, the link between walking behavior and the urban environment could be moderated by residential selfselection, or the tendency of individuals to choose walkable neighborhoods based on their wmobility preferences, which is not accounted for in this paper. As for the computation of the PIE itself, a variable from the original formulation had to be omitted in order to apply the measure at a metropolitan scale. This might weaken the measure's capacity to represent walkability in a modelling context. Further research should be carried out in areas where relevant data is available so that the effect of the absence of this variable can be assessed. Furthermore, the dataset used to compute the Urban Living Infrastructure variable, Environics Analytics' EAG Business Locations, is maintained by a private entity which does not make their data collection and validation processes public. This makes it difficult to assess the data's accuracy. Finally, the pedestrian itineraries used to measure trip distances are not observed itineraries but the product of a shortest path algorithm. This introduces imprecision in the analysis, although the calculated distances are arguably much closer to actual traveled distances than traditional Euclidean or Manhattan distances.

\section{CONCLUSION}

This paper makes several contributions to pedestrian travel behavior knowledge and modelling of the relationship between the urban form and active travel behavior. It examines the potential of the Pedestrian Index of the Environment (PIE), created in Portland, Oregon, to explain walking behavior for short trips in the Greater Montréal Area (GMA). This specific measure was chosen for its comprehensive use of six different neighborhood variables, five of which were operationalized at the GMA scale, as well as its conceptual strengths: the use of a decay function and modelling-based weighing, as well as its grid-based normalization approach.

The PIE's transfer to the GMA seems to confirm the measure's potential to help understand walking behavior in different urban and suburban contexts. The measure's correlation with walking behavior was unaffected by the use of new datasets and its implementation in a larger metropolitan area. Conceptually more complete than other measures, the PIE thus appears to be a transferrable and useful tool for measuring the association of the urban form with active travel behavior in the GMA and potentially other areas. This offers planners and practitioners a comprehensive measure that is conceptually rich to evaluate the walkability of urban and suburban environments at a metropolitan scale.

Ongoing research efforts focus on the development of an analysis framework to assess the transferability of other walkability measures such as those presented in the background section of this paper. Current research also seeks to examine the influence of each index's parameters decay functions, search radius, grid cell size and the like - on their explanatory power. For example, the PIE's weights might differ slightly by trip purpose. The same goes for internal weighing of the different variables, since it is determined by a modelling process. Other walkability indices are also transferred to the GMA in order to compare the performance of the PIE to that of existing measures. In addition, the issue of residential self-selection should be addressed in future research efforts. 


\section{ACKNOWLEDGEMENTS}

The authors wish to acknowledge the support and funding provided by the Natural 3 Sciences and Engineering Research Council of Canada (NSERC)'s Discovery Grant Program, the 4 partners of the Mobilité Chair - the Ville de Montréal, the Société de transport de Montréal (STM), 5 the Ministère des Transports, de la Mobilité durable et de l'Électrification des transports 6 (MTMDET) and the Agence métropolitaine de transport (AMT) - as well as the Fonds de 7 recherche du Québec - Nature et technologies (FRQNT). They would like to recognize Mr. Clinton 8 Chiavarini, from Metro Portland, for his extremely valuable input about the structure of the 9 Context Tool scores. They would also like to thank Dr. Robert Schneider, of the University of 10 Wisconsin-Milwaukee, and Mr. Christopher Muhs, now of DKS Associates, for their assistance 11 creating the initial PIE measure in Portland. 
7. REFERENCES

Buck, C., Tkaczick, T., Pitsiladis, Y., Bourdehaudhuij, I., Reisch, L., Ahrens, W., Pigeot, I., 2014. Objective Measures of the Built Environment and Physical Activity in Children: From Walkability to Moveability. Journal of Urban Health 92(1), 24-38.

Chapleau, R., Allard, B., Trépanier, M., Morency, C., 2001. Les logiciels d'enquête transport comme instruments incontournables de la planification analytique. Recherche - Transports - Sécurité 70, 59-77. Clifton, K.J., Singleton, P.A., Muhs, C.D., Schneider, R.J., 2016a. Development of destination choice models for pedestrian travel. Transportation Research Part A: Policy and Practice 94, 255-265.

Clifton, K.J., Singleton, P.A., Muhs, C.D., Schneider, R.J., 2016b. Representing pedestrian activity in travel demand models: Framework and application. Journal of Transport Geography 52, 111-122.

Clifton, K.J., Singleton, P.A., Muhs, C.D., Schneider, R.J., Lagerwey, P., 2013. Improving the Representation of the Pedestrian Environment in Travel Demand Models, Phase I. Oregon Transportation Research and Education Consortium, Portland, OR.

Communauté métropolitaine de Montréal, Observatoire Grand Montréal. Communauté métropolitaine de Montréal, Montréal.

Duncan, D.T., Aldstadt, J., Whalen, J., Melly, S.J., 2012. Validation of Walk Scores and Transit Scores for estimating neighborhood walkability and transit availability: a small-area analysis. GeoJournal 78(2), 407416.

Environics Analytics, 2012. Release Notes - EAG Business Locations - 2012. Environics Analytics.

Ewing, R., Cervero, R., 2010. Travel and the Built Environment: A Meta-Analysis. Journal of the American Planning Association 76(3), 265-294.

Freeman, L., Neckerman, K., Schwartz-Soicher, O., Quinn, J., Richards, C., Bader, M.D.M., Lovasi, G., Jack, D., Weiss, C., Konty, K., Arno, P., Viola, D., Kerker, B., Rundle, A.G., 2012. Neighborhood Walkability and Active Travel (Walking and Cycling) in New York City. Journal of Urban Health 90(4), 575-585.

Google, 2016. Overview | Static Transit. Google.

Haklay, M., 2010. How Good is Volunteered Geographical Information? A Comparative Study of OpenStreetMap and Ordnance Survey Datasets. Environment and Planning B: Planning and Design 37(4), 682-703.

Haklay, M., Basiouka, S., Antoniou, V., Ather, A., 2010. How Many Volunteers Does it Take to Map an Area Well? The Validity of Linus' Law to Volunteered Geographic Information. The Cartographic Journal 47(4), 315-322.

Handy, S., 2005. Critical assessment of the literature on the relationships among transportation, land use, and physical activity. Transportation Research Board and the Institute of Medicine Committee on Physical Activity, Health, Transportation, and Land Use. Resource paper for TRB Special Report 282.

Koschinsky, J., Talen, E., Alfonzo, M., Lee, S., 2016. How walkable is Walker's paradise? Environment and Planning B: Planning and Design.

Kuzmyak, J., Baber, C., Savory, D., 2006. Use of Walk Opportunities Index to Quantify Local Accessibility. Transportation Research Record: Journal of the Transportation Research Board 1977, 145-153.

Leinberger, C.B., Lynch, P., 2016. Foot Traffic Ahead: Ranking Walkable Urbanism in America's Largest Metros, In: Sm (Ed.). Center for Real Estate and Urban Analysis, The George Washington University School of Business, Washington, DC.

Luxen, D., Vetter, C., 2011. Real-time routing with OpenStreetMap data, Proceedings of the 19th ACM SIGSPATIAL International Conference on Advances in Geographic Information Systems. ACM, Chicago, Illinois, pp. 513-516.

Maghelal, P.K., Capp, C.J., 2011. Walkability: A Review of Existing Pedestrian Indices. URISA Journal 23(2), 5-19.

Manaugh, K., El-Geneidy, A., 2011. Validating walkability indices: How do different households respond to the walkability of their neighborhood? Transportation Research Part D: Transport and Environment 16(4), 309-315. 
Morency, C., Demers, M., Poliquin, E., 2014. Shifting short motorized trips to walking: The potential of active transportation for physical activity in Montreal. Journal of Transport \& Health 1(2), 100-107.

Morency, C., Trépanier, M., Tremblay, V., Martel Poliquin, É., 2011. Insights on the Determinants of Walk Trips Using Large Scale Travel Survey Data, T\&DI Congress 2011: Integrated Transportation and Development for a Better Tomorrow, Chicago, IL, ASCE, Reston, VA, pp. 1006-1015.

Oregon Metro, Metro Context Tool - State of the Centers. Oregon Metro.

Organisation mondiale de la Santé, 2000. Obésité : prévention et prise en charge de l'épidémie mondiale, Série de Rapports techniques OMS. Organisation mondiale de la Santé, Genève.

Porta, S., Renne, J.L., 2005. Linking urban design to sustainability: formal indicators of social urban sustainability field research in Perth, Western Australia. Urban Design International 10(1), 51-64.

Primerano, F., Taylor, M.A.P., Pitaksringkarn, L., Tisato, P., 2008. Defining and understanding trip chaining behaviour. Transportation 35(1), 55-72.

Saelens, B.E., Sallis, J.F., Frank, L.D., 2003. Environmental correlates of walking and cycling: Findings from the transportation, urban design, and planning literatures. Annals of Behavioral Medicine 25(2), 8091.

Secrétariat à l'enquête Origine-Destination, 2013. Enquête Origine-Destination 2013: La mobilité des personnes dans la région de Montréal, In: transport, A.m.d. (Ed.). Agence métropolitaine de transport, Montréal.

Singleton, P.A., Schneider, R.J., Muhs, C., Clifton, K.J., 2014. The Pedestrian Index of the Environment: Representing the Walking Environment in Planning Applications, Transportation Research Board 93rd Annual Meeting, Washington DC.

Statistique Canada, 2011. Data Quality and Confidentiality Standards and Guidelines (Public) - 2011 Census Dissemination. Statistique Canada, Ottawa, Ontario, Canada.

Statistique Canada, 2015. 2011 Census Technical Report - Coverage, In: sociale, D.d.m.d.e. (Ed.). Statistique Canada, Ottawa, Ontario, Canada.

Vale, D.S., Saraiva, M., Pereira, M., 2015. Active accessibility: A review of operational measures of walking and cycling accessibility. Journal of Transportation and Land Use 9(1).

Valiquette, F., 2010. Typologie des chaînes de déplacements et modélisation descriptive des systèmes d'activités des personnes, Département des génies civil, géologique et des mines. Polytechnique Montréal, Montréal, Québec, Canada.

Witten, K., Pearce, J., Day, P., 2011. Neighbourhood Destination Accessibility Index: A GIS Tool for Measuring Infrastructure Support for Neighbourhood Physical Activity. Environment and Planning A 43(1), 205-223.

Wong, B.Y.-M., Faulkner, G., Buliung, R., 2011. GIS measured environmental correlates of active school transport: A systematic review of 14 studies. International Journal of Behavioral Nutrition and Physical Activity 8(1), 1-22.

Yasmin, F., Morency, C., Roorda, M.J., 2015. Assessment of spatial transferability of an activity-based model, TASHA. Transportation Research Part A: Policy and Practice 78, 200-213.

Zielstra, D., Hochmair, H., 2012. Using Free and Proprietary Data to Compare Shortest-Path Lengths for

40 Effective Pedestrian Routing in Street Networks. Transportation Research Record: Journal of the

41 Transportation Research Board 2299, 41-47. 